Check for updates

Cite this: RSC Adv., 2018, 8, 13625

Received 1st March 2018

Accepted 13th March 2018

DOI: $10.1039 / \mathrm{c} 8 \mathrm{ra01810c}$

rsc.li/rsc-advances

\section{New insight into the selective photocatalytic oxidation of RhB through a strategy of modulating radical generation $\uparrow$}

\author{
Huijun Liang, ${ }^{\text {ab }}$ Shengnan Liu, ${ }^{a}$ Hucheng Zhang, (DD *a Xiaobing Wang (D) $^{a}$ \\ and Jianji Wang (DD *a
}

Rhodamine $\mathrm{B}(\mathrm{RhB})$ has often been used as a model pollutant, but its photocatalytic mechanism is still controversial. Herein, Ag NPs were sandwiched between CdS QDs and amorphous- $\mathrm{TiO}_{2}\left(\mathrm{a}-\mathrm{TiO}_{2}\right)$ with the intent to build a $\mathrm{CdS} / \mathrm{Ag} / \mathrm{a}-\mathrm{TiO}_{2}$ catalyst with highly selective oxidation activity. When rhodamine $\mathrm{B}$ (RhB) was used as the model organic compound, the $\mathrm{CdS} / \mathrm{Ag} / \mathrm{a}-\mathrm{TiO}_{2}$ composite can not only modulate radical generation but also improve the conversion ratio of $\mathrm{RhB}$ to rhodamine 110 (Rh-110) to as high as $82 \%$ at 80 min during the visible-light irradiation. A series of the radical scavenging experiments revealed that $\mathrm{CdS} / \mathrm{Ag} / \mathrm{a}-\mathrm{TiO}_{2}$ composites could modulate the effects of hydroxyl radicals $(\cdot \mathrm{OH})$ and superoxide anion radicals $\left(\cdot \mathrm{O}_{2}{ }^{-}\right)$at different reaction stages so that the overoxidation of $\mathrm{RhB}$ and $\mathrm{Rh}-110$ were repressed. Therefore, the transient state protection mechanism of selective oxidation of RhB was proposed to explain the reaction selectivity for $\mathrm{Rh}-110$. Although the effects of both $\cdot \mathrm{O}_{2}{ }^{-}$and $\cdot \mathrm{OH}$ are important during the photocatalytic selective oxidation of $\mathrm{RhB}$, it is shown that the selective oxidation of $\mathrm{RhB}$ would be performed when the effect of $\cdot \mathrm{O}_{2}{ }^{-}$is bigger than the $\cdot \mathrm{OH}$, if not, $\mathrm{RhB}$ would be oxidized unselectively. Meanwhile, this may provide a new strategy for modulating radical generation in the photocatalysis of water phases.

\section{Introduction}

As a model organic compound, rhodamine $\mathrm{B}(\mathrm{RhB})$ is often used for examining the activities of photocatalysts, ${ }^{\mathbf{1 , 2}}$ Up to now, there have been two views on the photocatalytic degradation mechanism of $\mathrm{RhB}$, one is chemisorption of functional groups, and the other is photosensitized degradation..$^{3-5}$ Nevertheless, the two views both assumed that the $N$-deethylation of RhB would compete with the destruction of conjugated xanthene structure resulting in the uncomplete (selective oxidation) or complete degradation of $\mathrm{RhB} .^{\mathbf{3 , 4 , 6 - 8}}$ However, according to the two photocatalytic degradation mechanisms, it is still difficult to control the oxidation process of $\mathrm{RhB}$ and obtain desired products (e.g. rhodamine 110, Rh-110). ${ }^{9}$

Heterogeneous photocatalysis of semiconducting metal oxides has been widely studied since Fujishima and Honda

${ }^{a}$ Collaborative Innovation Center of Henan Province for Green Manufacturing of Fine Chemicals, Key Laboratory of Green Chemical Media and Reactions, Ministry of Education, School of Chemistry and Chemical Engineering, Henan Normal University, Xinxiang, Henan 453007, P. R. China. E-mail: hzhang@htu.edu.cn; jwang@henannu.edu.cn

${ }^{b}$ College of Chemistry and Chemical Engineering, Xinxiang University, Xinxiang, Henan 453003, P. R. China

$\dagger$ Electronic supplementary information (ESI) available: Synthesis of a-TiO ${ }_{2}$, size distribution, TEM and elemental mapping images, element contents BET measures, UV-visible spectrum,. See DOI: 10.1039/c8ra01810c found the photoelectrochemistry of $\mathrm{TiO}_{2} \cdot{ }^{10}$ So far, photocatalytic oxidation with $\mathrm{O}_{2}$ has been extensively used for unselectively obtaining the complete mineralization of a variety of pollutants in gaseous and aqueous phases because of the milder reaction conditions, ease of scaling up, environmentally friendly properties, and relatively high economic efficiency. ${ }^{\mathbf{1 1 - 1 5}}$ Beyond that, the selective photocatalytic oxidation of pollutants or organics have also attracted attention in recent years because it can also produce high-valued chemicals, ${ }^{11,16,17}$ such as the selective oxidation of aromatic alcohols, ${ }^{11,17-20}$ aliphatic alcohols, ${ }^{21-25}$ alkenes and alkanes, ${ }^{26}$ amines, ${ }^{14,27}$ isoeugenol ${ }^{28}$ and so on.

However, it is well known that the photogenerated electrons $\left(\mathrm{e}^{-}\right)$and holes $\left(\mathrm{h}^{+}\right)$could react with dissolved oxygen $\left[\left(\mathrm{O}_{2}\right)_{\mathrm{aq}}\right]$ or hydroxyl $(-\mathrm{OH})$ on the surface of photocatalysts to produce various reactive oxygen species (ROS) during the reactions, such as hydroxyl radicals $(\cdot \mathrm{OH})$, superoxide anion radicals $\left(\cdot \mathrm{O}_{2}{ }^{-}\right)$, and $\mathrm{O}_{2}{ }^{-}$protonation radicals $(\cdot \mathrm{OOH})$, and so on. ${ }^{4,29}$ For example, when the $\mathrm{TiO}_{2}$ is used as photocatalyst under ultraviolet (UV) light irradiation, the formations of ROS can be described as follow: ${ }^{30-34}$

$$
\begin{gathered}
\mathrm{TiO}_{2}+h v \rightarrow \mathrm{e}^{-}+\mathrm{h}^{+} \\
\left(\mathrm{O}_{2}\right)_{\mathrm{aq}}+\mathrm{e}^{-} \rightarrow \cdot \mathrm{O}_{2}^{-}
\end{gathered}
$$




$$
\begin{gathered}
\mathrm{h}^{+}+\mathrm{H}_{2} \mathrm{O} \rightarrow \mathrm{H}^{+}+\cdot \mathrm{OH} \\
\mathrm{h}^{+}+\mathrm{OH}^{-} \rightleftharpoons \cdot \mathrm{OH} \\
\mathrm{O}_{2}^{-}+\mathrm{H}^{+} \rightarrow \cdot \mathrm{OOH} \\
\cdot \mathrm{OOH}+\cdot \mathrm{O}_{2}^{-}+\mathrm{H}^{+} \rightarrow \mathrm{O}_{2}+\mathrm{H}_{2} \mathrm{O}_{2} \\
\mathrm{H}_{2} \mathrm{O}_{2}+\cdot \mathrm{O}_{2}^{-} \rightarrow \cdot \mathrm{OH}+\mathrm{OH}^{-}+\mathrm{O}_{2}
\end{gathered}
$$

This suggests that the photogenerated $\mathrm{e}^{-}$and $\mathrm{h}^{+}$can be converted into the different ROS. In fact, the nonselective autooxidations of ROS involve in many parallel oxidation pathways during photocatalytic oxidations, ${ }^{35}$ the photocatalytic selectivity of desired products is usually very low when the produces or substrates are seriously oxidized by these ROS in the water phase. ${ }^{9,27,36,37}$ However, many reports have demonstrated that ROS have different oxidation potential, such as 2.80 or $2.7 \mathrm{~V}$ for $\cdot \mathrm{OH},{ }^{29,33} 1.76 \mathrm{~V}$ for $\mathrm{O}_{2}$ or $\mathrm{H}_{2} \mathrm{O}_{2},{ }^{6}$ and $-0.33 \mathrm{~V}$ for $\cdot \mathrm{O}_{2}{ }^{-, 29}$ indicating that ROS possess the different photocatalytic oxidation activity, hereinto, $\cdot \mathrm{OH}$ is the highest one according to the oxidation potential. Therefore, it is possible to perform the selective oxidation of $\mathrm{RhB}$ and improve the conversion ratio towards the Rh-110 through the decrease of $\cdot \mathrm{OH}$ during the photocatalytic oxidations. However, to the best of our knowledge, the mediating strategies for the selective generation of ROS are very few in the previous literature, and one of the main challenges is difficult to construct suitable framework for the blocks of photocatalysts. ${ }^{11,21}$

CdS quantum dots (QDs) respond sensitively to visible (Vis) light, ${ }^{19}$ and amorphous $\mathrm{TiO}_{2}\left(\mathrm{a}-\mathrm{TiO}_{2}\right)$ efficiently captures $\mathrm{h}^{+} .38,39$ As the photogenerated $\mathrm{h}^{+}$is directly trapped by $\mathrm{a}-\mathrm{TiO}_{2}$, the $\cdot \mathrm{OH}$ radicals of higher oxidation activity would be decreased according to equation (eqn (3) and (4)), further, the photoinduced stability of CdS QDs and the conversion ratio of selective photooxidation would be improved during the photocatalytic oxidation. ${ }^{40}$ Therefore, it is expected that $\mathrm{CdS} / \mathrm{a}-\mathrm{TiO}_{2}$ composite could be more favorable for enhancing the effect of $\cdot \mathrm{O}_{2}{ }^{-}$rather than the $\cdot \mathrm{OH}$ with higher oxidation activity in the photooxidation.

However, the spectral response range of CdS QDs is relatively narrow, ${ }^{41}$ and $\mathrm{a}^{-\mathrm{TiO}_{2}}$ in nature has the short range ordered structure and the high defect density. ${ }^{\mathbf{3 8 , 4 2}}$ These factors are very detrimental to the photocatalytic activity of $\mathrm{CdS} / \mathrm{a}-\mathrm{TiO}_{2}$ composites. It is well known that the localized surface plasmon resonance (LSPR) of noble metal nanoparticles (NPs) can induce a local electric field, increase the photocatalytic activity of a$\mathrm{TiO}_{2}$, and extend the light absorption range of CdS/a-TiO ${ }_{2}{ }^{43}$ Therefore, CdS/a- $\mathrm{TiO}_{2}$ composites containing noble metal NPs could be preferential catalysts for increasing the effect of $\cdot \mathrm{O}_{2}{ }^{-}$ and the conversion ratio of Rh-110.

In this work, the hydrosoluble CdS quantum dots (QDs) and $\mathrm{Ag}$ nanoparticles were loaded on $\mathrm{a}-\mathrm{TiO}_{2}$ with high specific surface area, and respectively to prepare CdS/a-TiO ${ }_{2}, \mathrm{CdS} / \mathrm{Ag} / \mathrm{a}$ $\mathrm{TiO}_{2}$ and $\mathrm{CdS} / \mathrm{Ag} / \mathrm{c}-\mathrm{TiO}_{2}$ composites. The selective photooxidation activities of catalysts were evaluated by the yield of Rh-110. It is shown that $\mathrm{CdS} / \mathrm{a}-\mathrm{TiO}_{2}$ and $\mathrm{CdS} / \mathrm{Ag} / \mathrm{a}-\mathrm{TiO}_{2}$ composites all exhibit the catalytic activity for the selective oxidation of rhodamine $\mathrm{B}$ under Vis-light irradiation. The conversion ratio of $\mathrm{CdS} / \mathrm{a}-\mathrm{TiO}_{2}$ is only about $9.7 \%$ in $100 \mathrm{~min}$, however, the conversion ratio of $\mathrm{CdS} / \mathrm{Ag} / \mathrm{a}-\mathrm{TiO}_{2}$ can reach to $82.4 \%$ in $80 \mathrm{~min}$. Compare with our previous report, $\mathrm{Ag} / \mathrm{a}-\mathrm{TiO}_{2}$ (which was labeled $\mathrm{Ag} / \mathrm{TiO}_{2}-\mathrm{I}$ in previous work) also has the selective oxidation performance, but the conversion ratio is only $23.8 \%$ in $180 \mathrm{~min} .{ }^{9}$ In order to insight into the roles played by $\cdot \mathrm{O}_{2}{ }^{-}, \cdot \mathrm{OH}$, and $\mathrm{h}^{+}$, the scavengers of benzoquinone (BQ), isopropanol (IPA), and triethanolamine (TEOA) were used respectively to remove $\cdot \mathrm{O}_{2}{ }^{-}, \cdot \mathrm{OH}$, and $\mathrm{h}^{+}$during the photocatalytic reaction. The scavenging experiments confirm that the ROS can be modulated by $\mathrm{CdS} / \mathrm{Ag} / \mathrm{a}-\mathrm{TiO}_{2}$ composite during the photocatalytic reaction, and the conversion ratio of $\mathrm{Rh}-100$ can be improved by the rational design of catalysts, so that the photocatalytic degradation mechanisms of RhB can be explained by the transient state protection mechanism of RhB.

\section{Experimental section}

Cadmium chloride $\left(\mathrm{CdCl}_{2} \cdot 2.5 \mathrm{H}_{2} \mathrm{O}, \mathrm{AR}\right)$ and absolute ethanol were purchased from Beijing Chemical Works (China). Ethylene glycol (EG, $\mathrm{HOCH}_{2} \mathrm{CH}_{2} \mathrm{OH}, \mathrm{AR}$ ) and tetrabutyl titanate (TBT, 98\%) were purchased from Sinopharm Chemical Reagent Co. Ltd. Acetic acid $\left(\mathrm{CH}_{3} \mathrm{COOH}, \mathrm{AR}\right)$ was purchased from Tianjin Deen Chemical Reagent Co. Ltd. Silver nitrate $\left(\mathrm{AgNO}_{3}, \mathrm{AR}\right)$ and thioacetamide (TAA) were purchased from Aladdin. RhB (AR) was purchased from Tianjin Kemiou Chemical Reagent Co., Ltd.

\subsection{Synthesis of CdS QDs and $\mathrm{a}^{-\mathrm{TiO}_{2}}$}

In a typical procedure, $2.08 \mathrm{~g}$ of $\mathrm{CdCl}_{2} \cdot 2.5 \mathrm{H}_{2} \mathrm{O}$ and $0.75 \mathrm{~g}$ of TAA were respectively dissolved into $100 \mathrm{~mL}$ absolute ethanol by means of ultrasonication, then two solutions were mixed with the ultrasonication for $10 \mathrm{~min}$ and let it stand for $4 \mathrm{~h}$ to form the CdS precursor at room temperature.

The as-prepared CdS precursor was added into $300 \mathrm{~mL}$ deionized water, and then heated to $40{ }^{\circ} \mathrm{C}$ for $8 \mathrm{~h}$ under magnetic stirring. The colour of solution changes from colorless to yellow. The precipitate was separated by centrifugation at $20000 \mathrm{rpm}$, and washed with deionized water and absolute ethanol several times, and finally dried in vacuum at $60{ }^{\circ} \mathrm{C}$ to obtain yellow hydrosoluble CdS QDs.

a- $-\mathrm{TiO}_{2}$ was synthesized by the processes as reported in our previous work, ${ }^{44}$ and also the details can be found in ESI S1. $\dagger$

\subsection{Synthesis of $\mathrm{CdS} / \mathrm{a}-\mathrm{TiO}_{2}$ and $\mathrm{CdS} / \mathrm{Ag} / \mathrm{a}-\mathrm{TiO}_{2}$ composites}

$2 \mathrm{~g} \mathrm{a}-\mathrm{TiO}_{2}$ was dispersed into $300 \mathrm{~mL}$ deionized water with the ultrasonication for $30 \mathrm{~min}$, and then irradiated by UV-light source for $2 \mathrm{~h}$. The color of suspension evolved gradually from white to black blue. After UV-light source was shut down, $50 \mathrm{~mL}$ aqueous solution containing $0.6 \mathrm{~g}$ of CdS QDs was added into the $\mathrm{a}-\mathrm{TiO}_{2}$ suspension under vigorously magnetic stirring for $1 \mathrm{~h}$. Then the precipitate was separated by centrifugation at $10000 \mathrm{rpm}$, and washed with deionized water and absolute 
ethanol several times, and finally dried in vacuum at $40{ }^{\circ} \mathrm{C}$ to obtain CdS/a- $\mathrm{TiO}_{2}$ composite.

After UV-light source was shut down, similarly, $20 \mathrm{~mL} \mathrm{AgNO}_{3}$ aqueous solution $\left(19.4 \mathrm{mmol} \mathrm{L}^{-1}\right)$ was mixed into the black blue $\mathrm{a}-\mathrm{TiO}_{2}$ under vigorously magnetic stirring for $1 \mathrm{~h}$ to obtain gray $\mathrm{Ag} / \mathrm{a}-\mathrm{TiO}_{2}$ composite. Then, $50 \mathrm{~mL}$ aqueous solution containing $0.6 \mathrm{~g}$ of CdS QDs was added into under stirring for $1 \mathrm{~h}$. After this, the precipitate was separated, washed, and dried following the same processes as mentioned above to harvest CdS/Ag/a$\mathrm{TiO}_{2}$ composite.

$\mathrm{CdS} / \mathrm{Ag} / \mathrm{c}-\mathrm{TiO}_{2}$ was prepared through annealing $\mathrm{CdS} / \mathrm{Ag} / \mathrm{a}-$ $\mathrm{TiO}_{2}$ at $300{ }^{\circ} \mathrm{C}$ for $4 \mathrm{~h}$ for comparison.

\subsection{Photochemical reactor and photocatalytic experiments}

The photochemical reactor system was consisted of a $30 \mathrm{~mL}$ quartz tube and a cylindrical water-cooled jacket quartz cell. A $500 \mathrm{~W}$ Xe-lamp or $500 \mathrm{~W}$ high-pressure mercury lamp was placed inside the quartz cell, which was respectively used as the Vis and UV-light source. The optical path length was $10 \mathrm{~cm}$. The cylindrical water-cooled jacket quartz cell was kept at $15 \pm 2{ }^{\circ} \mathrm{C}$ by an external cooling jacket with recycled water.

The photocatalytic degradation of $5 \mathrm{mg} \mathrm{L}^{-1} \mathrm{RhB}$ was used to evaluate the selective oxidation activities of as-synthesized samples and the effect of $\cdot \mathrm{O}_{2}{ }^{-}, \cdot \mathrm{OH}$, and $\mathrm{h}^{+}$. Typical, $25 \mathrm{~mL}$ $\mathrm{RhB}$ solution and $0.05 \mathrm{~g}$ catalysts were dispersed into $30 \mathrm{~mL}$ quartz tube under magnetically stirred and open to air, and were held in dark for $30 \mathrm{~min}$ to reach adsorption-desorption equilibrium. After irradiated by light for a certain time interval, $2 \mathrm{~mL}$ reaction mixture was centrifuged to remove the photocatalyst, and the degradation of $\mathrm{RhB}$ was evaluated by the intensity of adsorption peak at $554 \mathrm{~nm}$. The percentages of degradation is calculated as $C / C_{0} \times 100 \%$, here, $C$ is the intensity of the RhB solution at each irradiated time interval, and $C_{0}$ is the intensity of the initial concentration.

In order to simplify the calculation, the concentration of selective photooxidation product (Rh-110) was evaluated by the intensity of adsorption peak at $498 \mathrm{~nm}$ according to the molecular amount of converting RhB into Rh-110 (eqn (8)), and correspondingly the conversion ratio is also calculated as $C / C_{0}$ $\times 100 \%$. Especially, the conversion ratio was marked by blue pentagrams at the degradation efficiency curves only when the Rh-110 was generated. It means that the conversion ratio increase with increasing the concentration of Rh-110, but the degradation efficiency decrease.

In the same experimental conditions, a certain amount of benzoquinone (BQ), isopropanol (IPA), and triethanolamine (TEOA) were respectively added into the photocatalytic degradation system of $\mathrm{RhB}$ to evaluate the effect of $\cdot \mathrm{O}_{2}{ }^{-}, \cdot \mathrm{OH}$, and $\mathrm{h}^{+}$ according to the degradation percentage of RhB.

\subsection{Structural characterizations}

The as-prepared samples were characterized by the transmission electron microscope (TEM, JEOL JEM-2100), X-ray diffraction (XRD, Bruker advance-D8), X-ray photoelectron spectroscopy (XPS, VG Scientific ESCALAB MKII), and Brunauer-Emmet-Teller (BET) method and the Barrett-Joyner-
Halenda (BJH, Micromeritics Instruments ASAP 2020). Their properties were measured by the UV-Vis diffused reflectance spectra (DRS, Lambda 950, PerkinElmer Inc, America, and $\mathrm{BaSO}_{4}$ was used as a reflectance standard.), photoluminescence spectrophotometer (PL, HITACHI FP-6500 spectrophotometer), and UV-Vis spectrophotometry (TU-1900, Beijing). The elemental compositions of samples were investigated by the energy-dispersive X-ray spectroscopy (EDS) attached to the field emission scanning electron microscopy (FESEM, ZEISS SUPRA$40 \mathrm{VP})$.

\section{Results and discussions}

\subsection{Synthesis and characterizations of composites}

CdS QDs are usually synthesized by the organic phase or aqueous phase routes. By contrast, aqueous phase syntheses of CdS QDs are simpler and easily scaled up, but the resulting QDS often exhibit lower crystallinity and quantum yields. ${ }^{45,46}$ Here, the uniform hydrosoluble CdS QDs were synthesized by a facile hydrolysis method without surfactant. As shown from TEM images in Fig. 1a and b, the as-prepared CdS QDs have good dispersity and uniformity with the mean size about $5.4 \pm 0.2 \mathrm{~nm}$ (Fig. S1a $\dagger$ ). The lattice spacing of $0.336 \mathrm{~nm}$ corresponding to the (002) plan of CdS in high-resolution transmission electron micro (HRTEM) and the pattern of the selected area electron diffraction (SAED) confirm the resulting QDs possess good crystallinity.

When the CdS QDs were loaded on the surface of a- $\mathrm{TiO}_{2}$, the images in Fig. 1c and d show the relatively uniform distribution of CdS QDs with almost unchanged size of $5.6 \pm 0.2 \mathrm{~nm}$ (Fig. S1b †). As reported in our previous work, the light chemical reduction in aqueous $\mathrm{AgNO}_{3}$ solution can induce the growth of $\mathrm{Ag}$ NPs on the $\mathrm{a}-\mathrm{TiO}_{2}$ to produce $\mathrm{Ag} / \mathrm{a}-\mathrm{TiO}_{2}$ composite. ${ }^{9}$ It suggests that the $\mathrm{Ag}$ NPs on $\mathrm{Ag} / \mathrm{a}-\mathrm{TiO}_{2}$ composite can provide the good scaffolds to anchor CdS QDs through S-Ag chemical interactions. As a result, $\mathrm{CdS} / \mathrm{Ag} / \mathrm{a}-\mathrm{TiO}_{2}$ composite was facilely prepared by mixing $\mathrm{CdS}$ QDs with $\mathrm{Ag} / \mathrm{a}-\mathrm{TiO}_{2}$ suspension. Despite the stacking of CdS QDs on Ag NPs, the metal occurrence in $\mathrm{CdS} / \mathrm{Ag} / \mathrm{a}-\mathrm{TiO}_{2}$ composite could still be identifiable from the lattice spacing of $\mathrm{Ag}$ (111) crystal plane (corresponding to $0.236 \mathrm{~nm}$ in Fig. 1f) and a few Ag Nps with big particle size (Fig. $\mathrm{S} 2 \dagger$ ). As shown in Fig. $\mathrm{S} 2, \uparrow$ some representative Ag NPs show that CdS QDs are loaded on the Ag NPs (white arrows), and $\mathrm{Ag}$ NPs located at between CdS QDs and a-TiO 2 . The architecture was further confirmed by the similar distribution of $\mathrm{Cd}$ and $\mathrm{Ag}$ elements on $\mathrm{a}^{-\mathrm{TiO}_{2}}$ from the element mapping images of $\mathrm{CdS} / \mathrm{Ag} / \mathrm{a}-\mathrm{TiO}_{2}$ (Fig. S3†). After annealing CdS/Ag/a-TiO however, the geometric arrangement in the composite could be disarrayed to turn into the $\mathrm{CdS} / \mathrm{Ag} /$ crystalline $\mathrm{TiO}_{2}(\mathrm{CdS} / \mathrm{Ag} / \mathrm{c}-$ $\mathrm{TiO}_{2}$ ) composite, and hence $\mathrm{Ag}$ NPs were exposed on $\mathrm{TiO}_{2}$ and can be clearly observed from Fig. $1 \mathrm{~g}$ and $\mathrm{h}$. Simultaneously, the SAED images and the lattice spacing of $0.352 \mathrm{~nm}$ corresponding to the (101) plan of $\mathrm{TiO}_{2}$ verify the transformation of a-TiO${ }_{2}$ to crystalline $\mathrm{TiO}_{2}\left(\mathrm{c}-\mathrm{TiO}_{2}\right)$ after the annealing treatment of CdS/ $\mathrm{Ag} / \mathrm{a}-\mathrm{TiO}_{2}$.

The phase structure and composition of as-prepared samples were determined by XRD patterns and XPS spectra. 

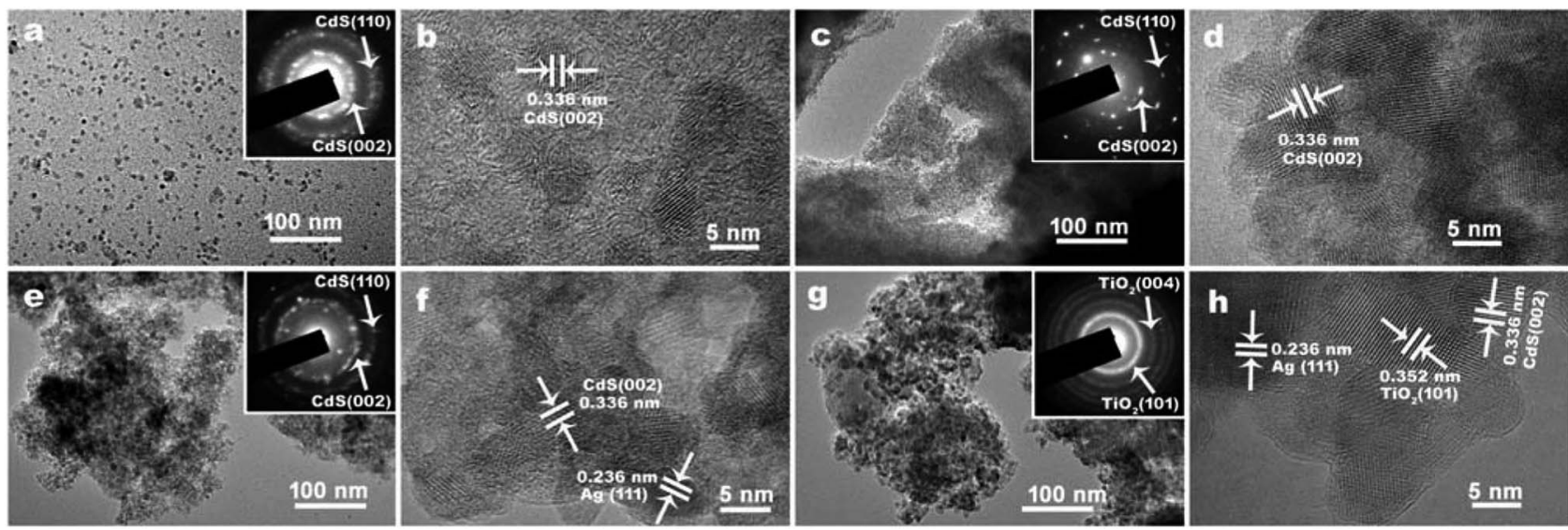

Fig. 1 The TEM and HRTEM images of as-prepared samples. (a) and (b) CdS QDs, (c) and (d) CdS/a-TiO ${ }_{2}$ (e) and (f) $\mathrm{CdS} / \mathrm{Ag} / \mathrm{a}-\mathrm{TiO}{ }_{2}$, (g) and (h) $\mathrm{CdS} / \mathrm{Ag} / \mathrm{c}-\mathrm{TiO}_{2}$. The insets are the ring patterns of the selected area electron diffraction (SAED) images.

As shown in Fig. 2a, the diffraction peaks show that CdS QDs represent a hexagonal phase (JCPDS card no. 41-1049), but the wide diffraction peaks of $\mathrm{CdS} / \mathrm{a}-\mathrm{TiO}_{2}$ and $\mathrm{CdS} / \mathrm{Ag} / \mathrm{a}-\mathrm{TiO}_{2}$ composites result from the a- $\mathrm{TiO}_{2}$ due to the low content of $\mathrm{CdS}$ and $\mathrm{Ag}$ beyond the instrumental detection limit. After annealing $\mathrm{CdS} / \mathrm{Ag} / \mathrm{a}-\mathrm{TiO}_{2}$, the diffraction pattern indicates that the anatase $\mathrm{TiO}_{2}$ occurs in CdS/Ag/c-TiO 2 (JCPDS no. 21-1272).

The survey scan XPS spectra of as-prepared samples clearly show the occurrence of the expected Ti, O, Cd, S, C, and $\mathrm{N}$ elements in the respective composite (Fig. $2 \mathrm{~b}$ and Table S1 $\dagger$ ). It is noted that $\mathrm{Cd}$ and $\mathrm{S}$ elements can be detected from all samples, but $\mathrm{N}$ element only from CdS QDs due to the presence of TAA ligands. The absence of $\mathrm{N} 1 \mathrm{~s}$ peak in the survey spectra of $\mathrm{CdS} / \mathrm{a}-\mathrm{TiO}_{2}, \mathrm{CdS} / \mathrm{Ag} / \mathrm{a}-\mathrm{TiO}_{2}$ and $\mathrm{CdS} / \mathrm{Ag} / \mathrm{c}-\mathrm{TiO}_{2}$ indicates the remove of TAA ligands, and reflects that the strong interactions of CdS with $\mathrm{a}-\mathrm{TiO}_{2}$ and $\mathrm{Ag}$ NPs cause the QDs almost "naked" in these composites.

The chemical states of Cd 3d, S 2p, Ti 2p, and Ag 3d in the asprepared samples show distinct differences in their highresolution XPS spectra (Fig. 2c-f), respectively. As shown in Fig. 2c, the XPS spectra of Cd 3d in CdS QDs shows that the Cd $3 \mathrm{~d}_{3 / 2}$ and $3 \mathrm{~d}_{5 / 2}$ peak can be divided into two peaks centered at $\sim 414.8 / 413.4$ and $\sim 408.0 / 406.6 \mathrm{eV}$, and the peak separation of $6.8 \mathrm{eV}$ corresponding to $\mathrm{Cd}^{2+}$. The peaks at $413.4 / 406.6 \mathrm{eV}$ are
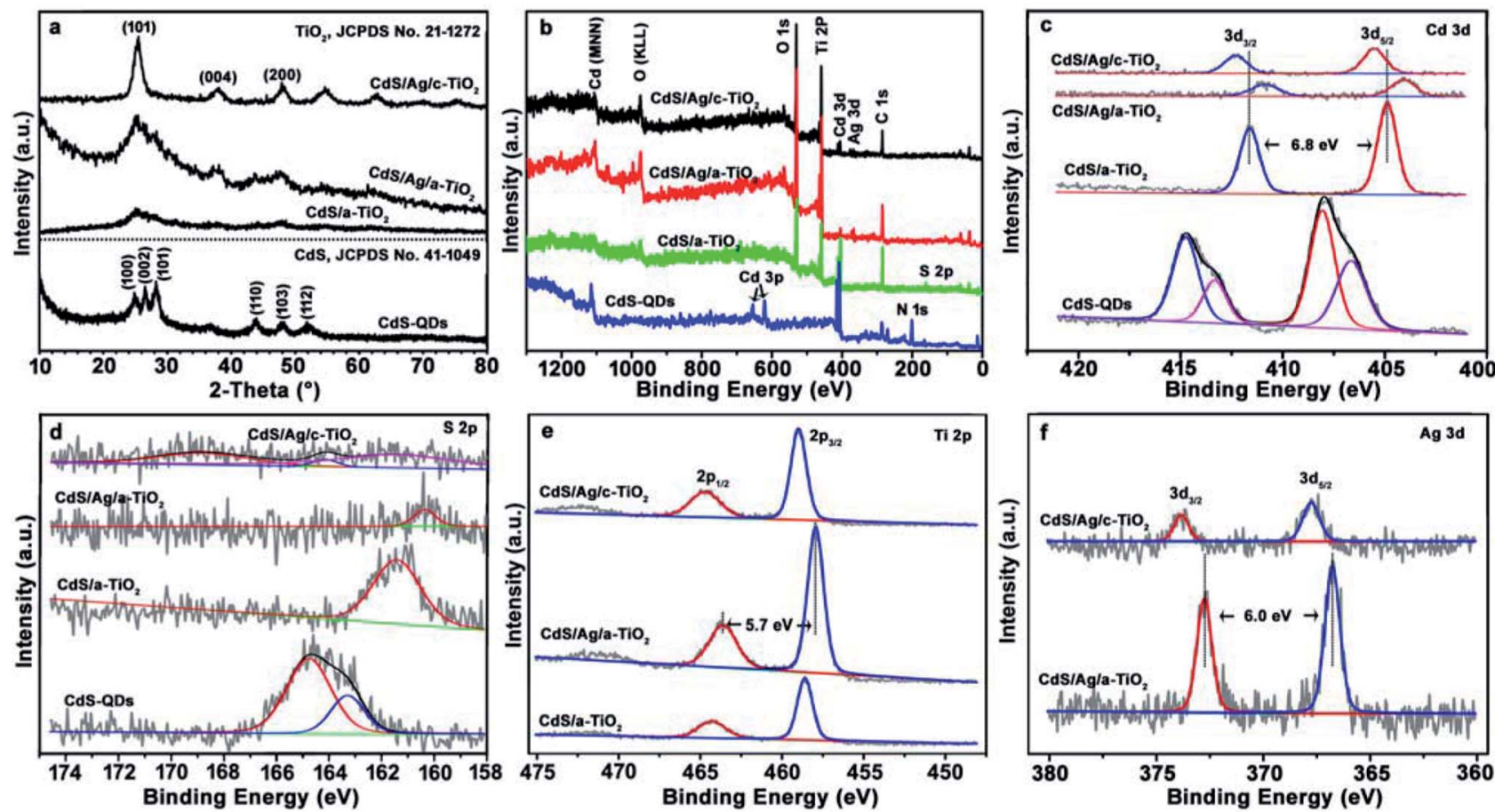

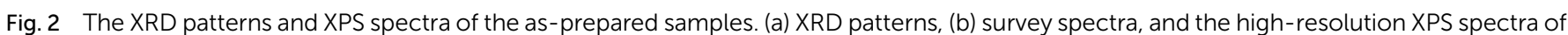
(c) Cd 3d, (d) S 2p; (e) Ti 2p; (f) Ag 3d. 
ascribed to $\mathrm{CdS}$, and the other at $414.8 / 408.0 \mathrm{eV}$ are combined with TAA ligands. ${ }^{47,48}$ When the CdS QDs are loaded on a-TiO ${ }_{2}$, the $\mathrm{Cd} 3 \mathrm{~d}_{3 / 2}$ and $\mathrm{Cd} 3 \mathrm{~d}_{5 / 2}$ appears as a single peaks in agreement with the remove of TAA, and the strong interactions cause the peak shift to $411.6 / 404.8 \mathrm{eV}$. Furthermore, the $\mathrm{Cd} 3 \mathrm{~d}$ peak is shifted to $410.9 / 404.1 \mathrm{eV}$ in $\mathrm{CdS} / \mathrm{Ag} / \mathrm{a}-\mathrm{TiO}_{2}$ due to the chemical bonding between $\mathrm{S}$ and $\mathrm{Ag}$ as the CdS QDs are loaded on $\mathrm{Ag} / \mathrm{a}$ $\mathrm{TiO}_{2}$, it means that the strong interactions between CdS QDs, Ag NPs and $\mathrm{a}-\mathrm{TiO}_{2}$ cause the peak shift of $\mathrm{Cd} 3 \mathrm{~d} .{ }^{\mathbf{4 9 , 5 0}}$ Correspondingly, the binding energy of $\mathrm{S} 2 \mathrm{p}$ exhibit the similar changes in pace with the enhanced interactions in the composites (Fig. 2d). By contrast, the $\mathrm{Cd} 3 \mathrm{~d}$ peak in $\mathrm{CdS} / \mathrm{Ag} / \mathrm{c}-\mathrm{TiO}_{2}$ reversely shifts to 412.3/405.5 eV, a binding energy more than that in $\mathrm{CdS} / \mathrm{a}-\mathrm{TiO}_{2}$, implying the collapse of stacking structure in $\mathrm{CdS} / \mathrm{Ag} / \mathrm{c}-\mathrm{TiO}_{2}$ due to the annealing treatment and the weaker interactions between $\mathrm{CdS}$ and $\mathrm{c}-\mathrm{TiO}_{2}$ in the resulting composite. Additionally, the architecture transformation of the three blockings during annealing can be verified from the high-resolution spectra of $\mathrm{Ti}$ and $\mathrm{Ag}$ elements: the $\mathrm{Ti} 2 \mathrm{p}$ peak shifts from $464.3 / 458.6 \mathrm{eV}$ in $\mathrm{CdS} / \mathrm{a}-\mathrm{TiO}_{2}$ to $463.6 / 457.9 \mathrm{eV}$ in $\mathrm{CdS} / \mathrm{Ag} / \mathrm{a}-\mathrm{TiO}_{2}$, then to $464.7 /$ $459.0 \mathrm{eV}$ in $\mathrm{CdS} / \mathrm{Ag} / \mathrm{c}-\mathrm{TiO}_{2}$, the $\mathrm{Ag} 3 \mathrm{~d}$ peak from $372.8 / 366.8 \mathrm{eV}$ in $\mathrm{CdS} / \mathrm{Ag} / \mathrm{a}-\mathrm{TiO}_{2}$ to $373.8 / 367.8 \mathrm{eV}$ in $\mathrm{CdS} / \mathrm{Ag} / \mathrm{c}-\mathrm{TiO}_{2}$ (Fig. 2e and f). ${ }^{51,52}$

Fig. 3 shows several optical properties of as-prepared samples. The pristine CdS QDs and CdS/a-TiO ${ }_{2}$ exhibit a Vislight absorption edge at about $450 \mathrm{~nm}$ (Fig. 3a), resulting from the intrinsic band-gap transition of electron from the valence band (VB) to the conduction band (CB) in CdS. ${ }^{53}$ When $\mathrm{Ag}$ NPs are added into $\mathrm{CdS} / \mathrm{a}-\mathrm{TiO}_{2}$, the synergistic effect of the LSPR with the light absorption of CdS QDs promotes the absorption of $\mathrm{CdS} / \mathrm{Ag} / \mathrm{a}-\mathrm{TiO}_{2}$ and $\mathrm{CdS} / \mathrm{Ag} / \mathrm{c}-\mathrm{TiO}_{2}$ composites extends over wider Vis-light region. ${ }^{47,54,55}$ The band gap $\left(E_{\mathrm{g}}\right)$ of CdS QDs, CdS/a- $\mathrm{TiO}_{2}$, and $\mathrm{CdS} / \mathrm{Ag} / \mathrm{a}-\mathrm{TiO}_{2}$ is respectively estimated to be $2.5,3.1$, and $2.7 \mathrm{eV}$ by Tauc plot of $(A h \nu)^{2} v s$. $h \nu$ (Fig. S4a $\dagger$ ). ${ }^{52,56,57}$

The emission intensity of photoluminescence (PL) spectra demonstrates the concentration of charge carriers in the excited states of composites. As excited by $386 \mathrm{~nm}$, the as-prepared CdS QDs exhibit two main emission peaks located at 487 and $531 \mathrm{~nm}$ (Fig. 3b) that originate from the excitonic recombination. ${ }^{55}$ The relative emission intensities of CdS hold strong in $\mathrm{CdS} / \mathrm{a}-\mathrm{TiO}_{2}$, but significantly are weaken in $\mathrm{CdS} / \mathrm{Ag} / \mathrm{a}-\mathrm{TiO}_{2}$ and $\mathrm{CdS} / \mathrm{Ag} / \mathrm{c}-\mathrm{TiO}_{2}$, and particularly in $\mathrm{CdS} / \mathrm{Ag} / \mathrm{a}-\mathrm{TiO}_{2}$. This suggests that the introduction of $\mathrm{Ag}$ NPs between $\mathrm{CdS}$ and $\mathrm{a}^{-\mathrm{TiO}_{2}}$ can moderately restrain the combination of photogenerated holes
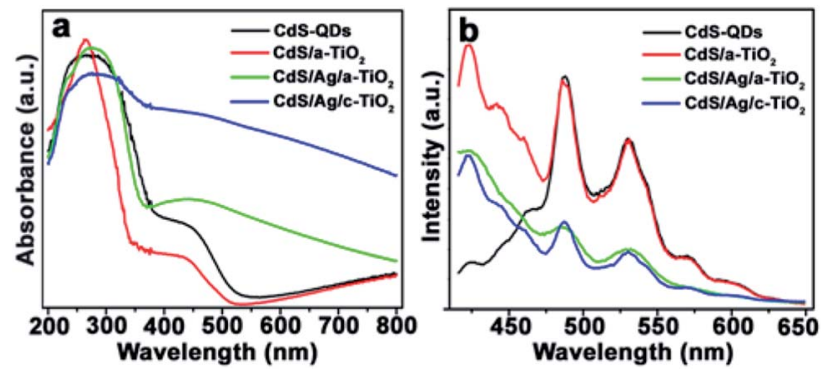

Fig. 3 (a) UV-Vis DRS, and (b) PL spectra of as-prepared composites. and electrons, ${ }^{58}$ and is expected to modulate ROS and to perform selective photocatalysis. The excited state electron radioactive decay lifetime of samples can also confirm the inhibition of $\mathrm{Ag}$ in $\mathrm{CdS} / \mathrm{Ag} / \mathrm{a}-\mathrm{TiO}_{2}$. As shown in Fig. $\mathrm{S} 4 \mathrm{~b}, \dagger$ the calculated average lifetime of CdS QDs, CdS/a-TiO ${ }_{2}, \mathrm{CdS} / \mathrm{Ag} / \mathrm{a}-$ $\mathrm{TiO}_{2}$ and $\mathrm{CdS} / \mathrm{Ag} / \mathrm{c}-\mathrm{TiO}_{2}$ are 3.5, 4.4, 4.3 and $4.9 \mathrm{~ns}$, respectively. The lifetime of CdS/Ag/a-TiO ${ }_{2}$ is longer than the CdS QDs.

In addition, the specific surface area, pore volume and average pore size of the composites were measured by the nitrogen adsorption/desorption experiments (Fig. S5 and Table $\mathrm{S} 2 \dagger)$. Among these composites, $\mathrm{CdS} / \mathrm{Ag} / \mathrm{a}-\mathrm{TiO}_{2}$ with the medium pore size exhibits the largest BET surface area of $441 \mathrm{~m}^{2} \mathrm{~g}^{-1}$ and pore volume of $0.35 \mathrm{~cm}^{3} \mathrm{~g}^{-1}$, and can provide the optimal space for available photocatalystic reactions.

\subsection{Selective photocatalytic oxidation of $\mathrm{RhB}$}

When $\mathrm{CdS} / \mathrm{a}-\mathrm{TiO}_{2}, \mathrm{CdS} / \mathrm{Ag} / \mathrm{a}-\mathrm{TiO}_{2}$, and $\mathrm{CdS} / \mathrm{Ag} / \mathrm{c}-\mathrm{TiO}_{2}$ were respectively used as photocatalysts, and correspondingly the changes of UV-Vis spectrum and degradation efficiency with time were recorded from the RhB aqueous solution during the photooxidation (Fig. 4). As far as Vis-light irradiation is concerned, the maximum absorption wavelength $\left(\lambda_{\max }\right)$ of $\mathrm{RhB}$ solution in the presence of $\mathrm{CdS} / \mathrm{a}-\mathrm{TiO}_{2}$ blue-shifts from 554 to $498 \mathrm{~nm}$ (Fig. 4a), indicating the formation of Rh-110 and the selective photocatalytic oxidation toward RhB. ${ }^{9}$ Although the conversion ratio of Rh-110 is only about $9.7 \%$ at $100 \mathrm{~min}, \mathrm{CdS} / \mathrm{a}-$ $\mathrm{TiO}_{2}$ exhibits the highest degradation efficiency compared with the other photocatalysts (Fig. 4d). CdS/Ag/a-TiO 2 represents the most efficient selective photocatalysis (Fig. $4 \mathrm{~b}$ and d). The $\lambda_{\max }$ of RhB solution blue-shifts to $510 \mathrm{~nm}$ only in $20 \mathrm{~min}$ that is attributed to the photoisomerization of dye chromophores, an intermediate for the conversion from RhB to Rh-110.,.$^{\mathbf{1 , 2 , 4 , 9 3 3 , 5 9}}$ After $20 \mathrm{~min}$, the peak intensity at $\lambda_{\max }$ of Rh-110 increases with irradiation time, and reaches the maximum (at $80 \mathrm{~min}$ ) that almost equates to the peak intensity of $\mathrm{RhB}$ in the adsorptiondesorption equilibrium solution (corresponding to the absorption peak intensity at $0 \mathrm{~min}$ in Fig. $4 \mathrm{~b}$ ). At this phase, the conversion ratio for $\mathrm{Rh}-110$ is about $82 \%$, subsequently, the peak intensity at $498 \mathrm{~nm}$ reduces gradually due to the degradation of Rh-110 with increasing irradiation time from 80 to $140 \mathrm{~min}$. Unlike CdS/Ag/a-TiO ${ }_{2}$, however, no photocatalysis of the selective oxidation is observed from the $\mathrm{CdS} / \mathrm{Ag} / \mathrm{c}-\mathrm{TiO}_{2}$ (Fig. 4c and d), and also its photocatalytic degradation efficiency is lower than $\mathrm{CdS} / \mathrm{a}-\mathrm{TiO}_{2}$. The experimental facts suggest that the special geometric arrangement in $\mathrm{CdS} / \mathrm{Ag} / \mathrm{a}-\mathrm{TiO}_{2}$ is responsible for the selective photocatalytic conversion from RhB to Rh110 with Vis-light irradiation.

When the RhB solution was degraded by UV-light irradiation, both CdS/a-TiO ${ }_{2}$ and $\mathrm{CdS} / \mathrm{Ag} / \mathrm{c}-\mathrm{TiO}_{2}$ exhibit the high photocatalytic degradation efficiency (Fig. $4 \mathrm{e}, \mathrm{g}$ and $\mathrm{h}$ ), and the RhB solution almost completely become colorless in $140 \mathrm{~min}$, but the selective oxidation product of Rh-110 was not detected from the photocatalysis. When the $\mathrm{CdS} / \mathrm{Ag} / \mathrm{a}-\mathrm{TiO}_{2}$ is used as photocatalyst, by contrast, the blue-shift of $\lambda_{\max }$ for RhB solution can be observed, and the conversion ratio from $\mathrm{RhB}$ to $\mathrm{Rh}-110$ is estimated to be $43 \%$ at 140 min (Fig. $4 \mathrm{f}$ and h), a value much 

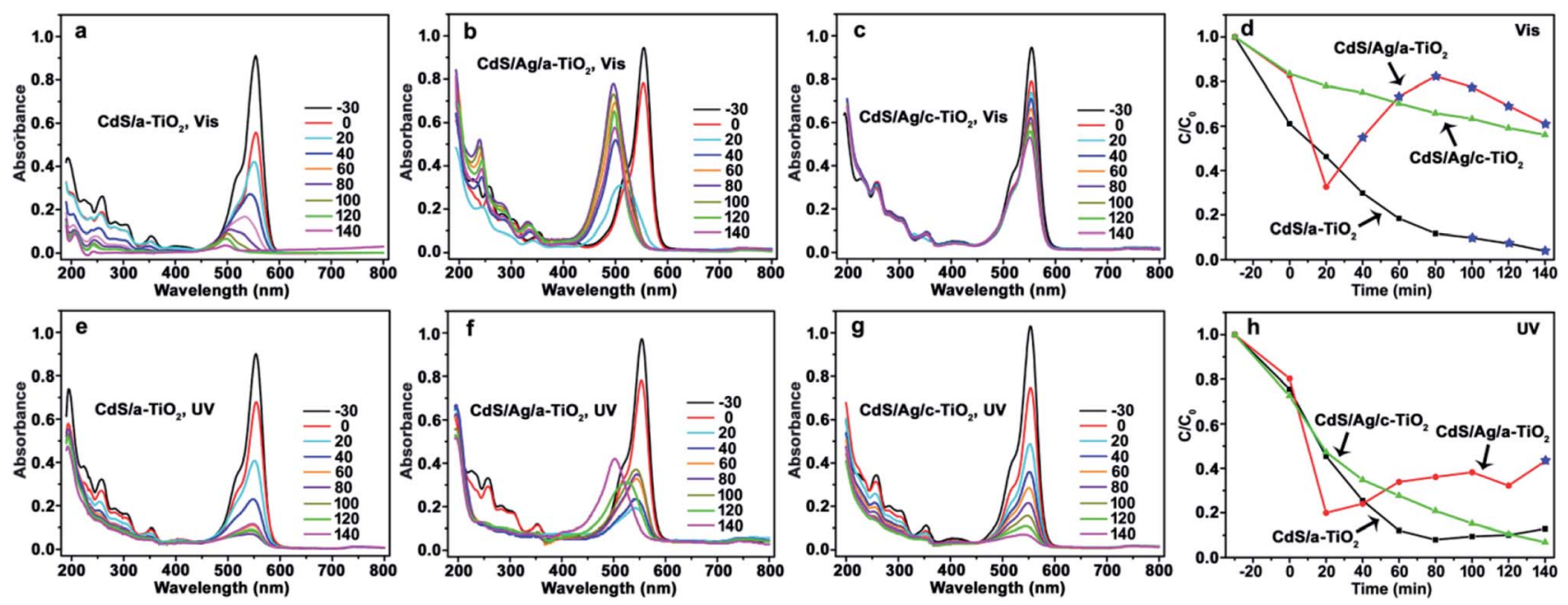

Fig. 4 Evolution of UV-Vis spectrum and photocatalytic degradation efficiency of RhB using the different photocatalysts and irradiation light sources. (a) $\mathrm{CdS} / \mathrm{a}-\mathrm{TiO}_{2}$, (b) $\mathrm{CdS} / \mathrm{Ag} / \mathrm{a}-\mathrm{TiO}_{2}$, (c) $\mathrm{CdS} / \mathrm{Ag} / \mathrm{c}-\mathrm{TiO}_{2}$, (d) degradation efficiency under Vis-light; and (e) $\mathrm{CdS} / \mathrm{a}-\mathrm{TiO}$, (f) $\mathrm{CdS} / \mathrm{Ag} / \mathrm{a}-\mathrm{TiO} 2$, (g) $\mathrm{CdS} / \mathrm{Ag} / \mathrm{c}-\mathrm{TiO}_{2}$, (h) degradation efficiency under UV-light. The conversion ratio of Rh-110 was marked by the blue pentagrams at the corresponding degradation efficiency curves ( $d$ and $h$ ).

less than that obtained from Vis-light irradiation. Therefore, $\mathrm{CdS} / \mathrm{Ag} / \mathrm{a}-\mathrm{TiO}_{2}$ is a preferential photocatalyst for the selective oxidation through UV- and Vis-light treatment, and demonstrates the great selectivity and activity under Vis-light irradiation.

\subsection{Modulating ROS and the photocatalytic mechanism of RhB}

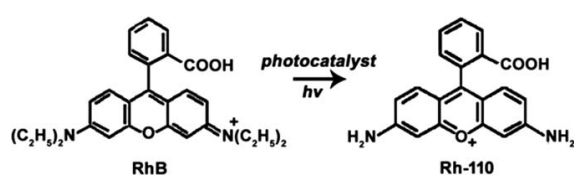

$\mathrm{RhB}$ as a model organic compound has been widely used to evaluate the photocatalytic degradation reaction because $\mathrm{RhB}$ could be not only completely degraded but also selectively photooxidized to produce Rh-110 (eqn (8)). ${ }^{1,2,4,7,33}$ In our previous report, we demonstrated that $\mathrm{RhB}$ could be selectively oxidized using Vis-light source and $\mathrm{Ag} / \mathrm{a}-\mathrm{TiO}_{2}$ photocatalyst to harvest Rh-110 with the conversion ratio of $23.8 \%$ in 180 min. ${ }^{9}$ Under three light-emitting diode (LED, $1 \mathrm{~W}$, radiant wavelength of 455-460 nm), alternatively, it is shown that both $\mathrm{Ag} / \mathrm{a}-\mathrm{TiO}_{2}$ (Fig. S6a $\dagger$ ) and $\mathrm{Ag} / \mathrm{c}^{-\mathrm{TiO}_{2}}$ (Fig. S6b广) can act as photocatalyst for selective oxidation, and the conversion ratio for $\mathrm{Rh}-110$ is $39 \%$ at $40 \mathrm{~min}$ using $\mathrm{Ag} / \mathrm{a}-\mathrm{TiO}_{2}$ and is $14 \%$ at $80 \mathrm{~min}$ using $\mathrm{Ag} / \mathrm{c}-\mathrm{TiO}_{2}$. Unfortunately, it is the low conversion ratio that limits the practical applications of the selective photocatalytic oxidations.

Herein, $\mathrm{CdS} / \mathrm{Ag} / \mathrm{a}-\mathrm{TiO}_{2}$ not only exhibits the wider light absorption range, but also the much higher selective oxidation activity with the conversion ratio of $82 \%$ for Rh-110 under Vislight irradiation. Based on eqn (1) to (7), it is believed that $\mathrm{CdS} / \mathrm{Ag} / \mathrm{a}-\mathrm{TiO}_{2}$ could promote the generation of $\cdot \mathrm{O}_{2}{ }^{-}$, but depress the increase of $\cdot \mathrm{OH}$. In order to insight into the controlling mechanisms of selective photocatalytic oxidation of $\mathrm{RhB}$, benzoquinone (BQ), isopropanol (IPA), and triethanolamine (TEOA) are used as scavengers respectively to remove $\cdot \mathrm{O}_{2}{ }^{-}, \cdot \mathrm{OH}$, and $\mathrm{h}^{+}$under the different light-sources, ${ }^{60,61}$ and the UV-Vis adsorption spectra of RhB solution and degradation efficiencies are shown in Fig. 5, 6 and 8 when the CdS/a-TiO $\mathrm{CdS} / \mathrm{Ag} / \mathrm{a}-\mathrm{TiO}_{2}$, and $\mathrm{CdS} / \mathrm{Ag} / \mathrm{c}-\mathrm{TiO}_{2}$ were respectively used as photocatalyst.

The photocatalysis of $\mathrm{CdS} / \mathrm{a}-\mathrm{TiO}_{2}$ in the presence of scavengers is shown in Fig. 5. After BQ and TEOA scavenge $\cdot \mathrm{O}_{2}{ }^{-}$and $\mathrm{h}^{+}$, the obvious blue-shift of $\lambda_{\max }$ is not observed from RhB solution under Vis (Fig. 5a and c) and UV-light (Fig. 5e and g) irradiation, and the photocatalytic degradation rate is remarkably decreased under Vis-light irradiation (Fig. 5d), suggesting that both $\cdot \mathrm{O}_{2}{ }^{-}$and $\mathrm{h}^{+}$are important for the selective photocatalytic conversion of RhB to Rh-110. In addition, as shown in Fig. $5 \mathrm{~d}$, the effects of $\mathrm{h}^{+}$is almost consistent with the $\cdot \mathrm{O}_{2}{ }^{-}$ (green and blue line), it suggesting that the photooxidized activities of $\mathrm{h}^{+}$and $\cdot \mathrm{O}_{2}{ }^{-}$in using $\mathrm{CdS} / \mathrm{a}-\mathrm{TiO}_{2}$ catalyst are almost identical under Vis-light irradiation.

In fact, according to the eqn (3) to (7), we propose that the effects of $\mathrm{h}^{+}$can be considered together with the $\cdot \mathrm{O}_{2}{ }^{-}$and $\cdot \mathrm{OH}$, that is, the effects of $\cdot \mathrm{O}_{2}{ }^{-}$and $\cdot \mathrm{OH}$ are considered mainly. Although $\mathrm{h}^{+}$itself has certain photooxidized activity (which is decided by the valence band position of materials.), the effects of $\mathrm{h}^{+}$can be final converted into the $\cdot \mathrm{O}_{2}{ }^{-}$and $\cdot \mathrm{OH}$ according to the eqn (3) to (7). It means that the effects of $\cdot \mathrm{O}_{2}{ }^{-}$and $\cdot \mathrm{OH}$ are simultaneous changed with the $\mathrm{h}^{+}$. Therefore, in order to simplify discussion, the effects (or amount) of $\cdot \mathrm{O}_{2}{ }^{-}$and $\cdot \mathrm{OH}$ are considered mainly in this work. Moreover, according to the simultaneous changed of $\cdot \mathrm{O}_{2}{ }^{-}$and $\cdot \mathrm{OH}$ with the $\mathrm{h}^{+}$, the curve overlapping of $\cdot \mathrm{O}_{2}^{-}$(Fig. $5 \mathrm{~d}, \mathrm{BQ}$ ) and $\mathrm{h}^{+}$(Fig. $5 \mathrm{~d}$, TEOA) is easy explained. Under Vis-light irradiation, $\mathrm{a}_{-} \mathrm{TiO}_{2}$ is not excited by the Vis-light, the photogenerated $\mathrm{e}^{-}$and $\mathrm{h}^{+}$is mainly originated 

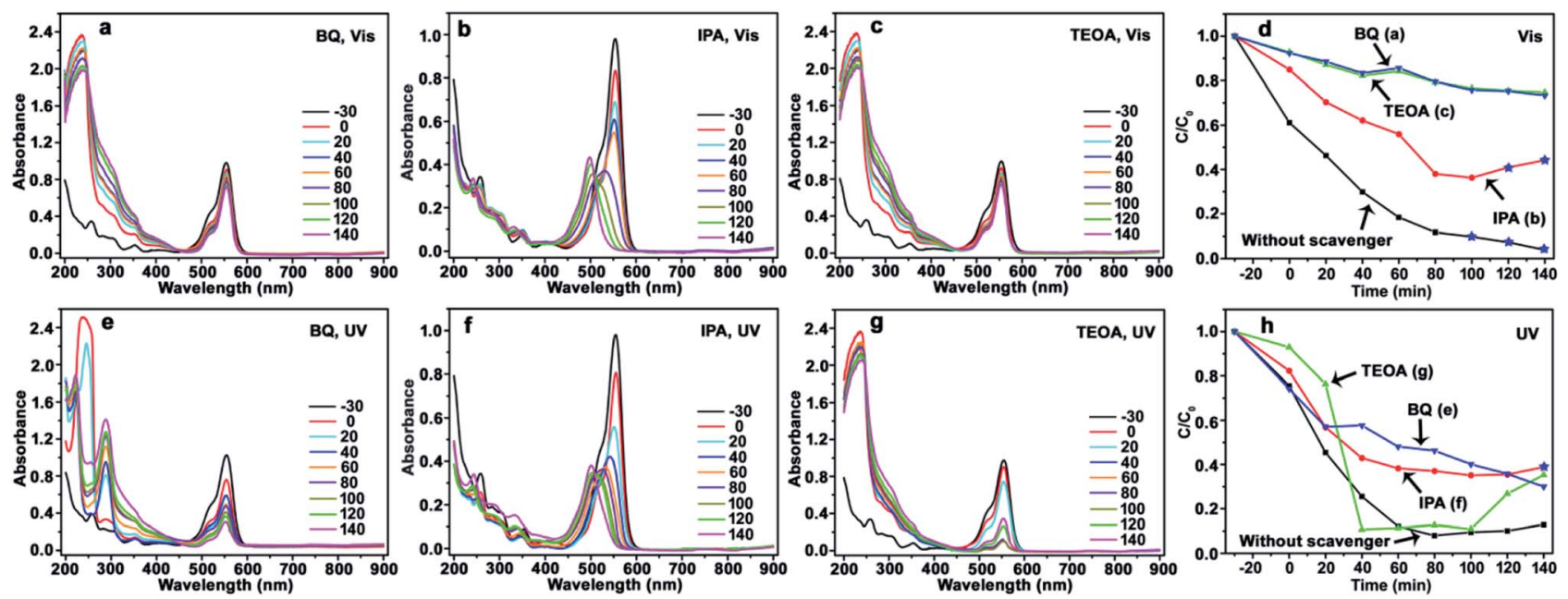

Fig. 5 Evolution of UV-Vis spectrum and photocatalytic degradation efficiency of RhB using $\mathrm{CdS} / \mathrm{a}-\mathrm{TiO}_{2}$ photocatalyst. Scavengers: $\mathrm{BQ}$ (a), IPA (b), TEOA (c), and the corresponding degradation efficiency (d) under Vis-light; BQ (e), IPA (f), TEOA (g), and the corresponding degradation efficiency ( $h$ ) under UV-light. The degradation efficiency curves without scavenger is inserted into (d) and (h) for comparison. The conversion ratio of Rh-110 was marked by the blue pentagrams at the corresponding degradation efficiency curves ( $d$ and $h$ ).

from CdS QDs. The photogenerated $\mathrm{e}^{-}$on the surface of CdS QDs can be scavenged by surface-adsorbed oxygen (eqn (2)), and $\mathrm{h}^{+}$can be left in the CdS QDs. ${ }^{62}$ When the $\mathrm{h}^{+}$is scavenged, the amount of $\cdot \mathrm{O}_{2}{ }^{-}$and $\cdot \mathrm{OH}$ also simultaneous decrease, so that the curves of $\cdot \mathrm{O}_{2}^{-}$and $\mathrm{h}^{+}$are accidentally overlapped.

Using IPA as scavenger to remove $\cdot \mathrm{OH}$, by contrast, the $\lambda_{\max }$ of RhB solution exhibit obvious blue-shifts under both Vis (Fig. 5b) and UV-light (Fig. 5f) irradiation, and the conversion ratio of Rh-110 can reach to $44 \%$ at 140 min under Vis-light irradiation. Compared with the conversion ratio of $9.7 \%$ for $\mathrm{CdS} / \mathrm{a}-\mathrm{TiO}_{2}$ (Fig. 4a and d), the scavenging of $\cdot \mathrm{OH}$ further improve the conversion ratio of Rh-110, suggesting that the scavenging of $\cdot \mathrm{OH}$ with the high photooxidized activity decreases the overoxidation of product (Rh-110) and substance $(\mathrm{RhB})$ due to the high photooxidized activity of $\cdot \mathrm{OH}$.

According to the photocatalytic degradation curve of $\mathrm{RhB}$ (Fig. $5 \mathrm{~d}$ and $\mathrm{h}$ ), one rule of selective photocatalytic oxidation can also be obtained, that is, the selective photocatalytic oxidation of $\mathrm{RhB}$ can be performed when the effect (or amount) of $\cdot \mathrm{O}_{2}{ }^{-}$is bigger than the $\cdot \mathrm{OH}$ in the reaction system, if not, $\mathrm{RhB}$ will be complete oxidized. As shown in Fig. 5 d, the effect of $\cdot \mathrm{O}_{2}{ }^{-}$is bigger than the $\cdot \mathrm{OH}$ under Vis-light irradiation, so that the selective photocatalytic oxidation of RhB can be performed by the pure $\mathrm{CdS} / \mathrm{a}-\mathrm{TiO}_{2}$ (Fig. 4a).

However, as shown in Fig. 4e, the blue-shift of $\lambda_{\max }$ is not observed. It can be attributed to the overoxidation of substance
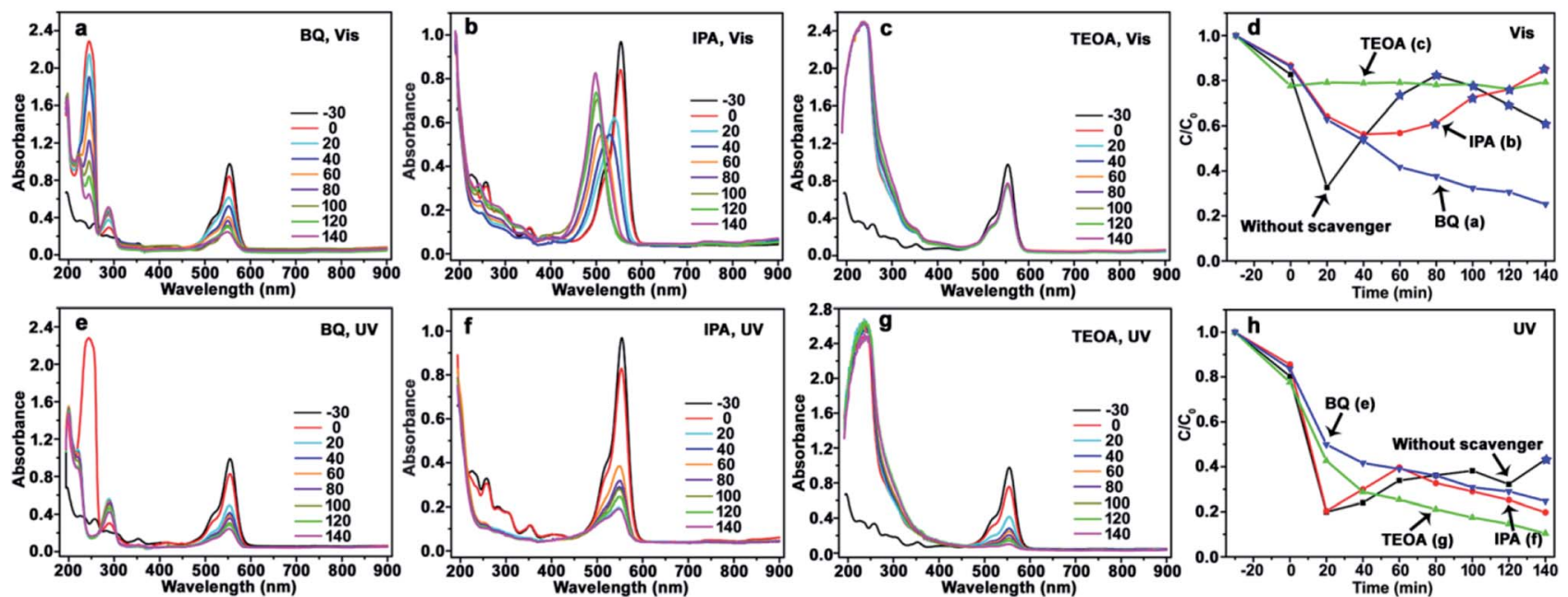

Fig. 6 Evolution of UV-Vis spectrum and photocatalytic degradation efficiency of RhB using CdS/Ag/a-TiO 2 photocatalyst. Scavengers: $\mathrm{BQ}$ (a), IPA (b), TEOA (c), and the corresponding degradation efficiency (d) under Vis-light; BQ (e), IPA (f), TEOA (g), and the corresponding degradation efficiency ( $h$ ) under UV-light. The degradation efficiency curves without scavenger is inserted into (d) and (h) for comparison. The conversion ratio of Rh-110 was marked by the blue pentagrams at the corresponding degradation efficiency curves ( $d$ and $h$ ). 
(RhB) at the initial stage of UV-light irradiation. Because the effect of $\cdot \mathrm{OH}$ is bigger than the $\cdot \mathrm{O}_{2}{ }^{-}$before $20 \mathrm{~min}$, a large number of RhB could have been complete oxidized at the initial stage, and Rh-110 cannot be obtained. In order to test this speculation, we performed a controlled experiment at same condition except for changing the concentration of $\mathrm{RhB}$ to $10 \mathrm{mg} \mathrm{L}^{-1}$. As shown in Fig. S7(see ESI $\dagger$ ), Rh-110 is generated at $330 \mathrm{~min}$. Therefore, the scavenging of $\cdot \mathrm{OH}$ is benefit to avoid the overoxidation of substance or product and improve the conversion ratio of product. As shown in Fig. 5f, when the $\cdot \mathrm{OH}$ is scavenged, the Rh-110 is obtained again at $140 \mathrm{~min}$.

The similar phenomenon can be observed in the photocatalysis of $\mathrm{CdS} / \mathrm{Ag} / \mathrm{a}-\mathrm{TiO}_{2}$. As shown in Fig. 6, the blue-shift of $\lambda_{\max }$ is not observed from $\mathrm{RhB}$ solution after scavenging $\cdot \mathrm{O}_{2}{ }^{-}$ (Fig. 6a and e) and $\mathrm{h}^{+}$(Fig. $6 \mathrm{c}$ and g). In contrast, the $\lambda_{\max }$ of RhB solution exhibit obvious blue-shift under Vis-light irradiation (Fig. 6b). However, the blue-shift of $\lambda_{\max }$ disappear when the . $\mathrm{OH}$ is scavenged UV-light irradiation (Fig. 6f). This phenomenon can be explained easily by the transient state protection mechanism, and obtaining the other rule of selective photocatalytic oxidation. That is, both $\cdot \mathrm{O}_{2}{ }^{-}$and $\cdot \mathrm{OH}$ are important for the selective photocatalytic conversion of RhB to Rh-110, the conversion ratio of Rh-110 can be improved when the effect (or amount) of $\cdot \mathrm{OH}$ is suitable increased at the later stage.

In the previous work, we proposed that the effect of $\cdot \mathrm{O}_{2}{ }^{-}$is more important than the $\cdot \mathrm{OH}$ during the process of forming Rh-110, because the conjugated xanthene structure of RhB could react with $\cdot \mathrm{O}_{2}{ }^{-}$to first form a transient state. ${ }^{9}$ This transient state can protect the conjugated xanthene structure of RhB from damage, so that only $N$-deethylation reaction of $\mathrm{RhB}$ can be performed by $\cdot \mathrm{OH}$ to form $\mathrm{Rh}-110$. In contrast, when the effect of $\cdot \mathrm{OH}$ is bigger than $\cdot \mathrm{O}_{2}{ }^{-}$, the conjugated xanthene structure of $\mathrm{RhB}$ is first damaged by the $\cdot \mathrm{OH}$, so that the transient state of conjugated xanthene structure of RhB is not produced, Rh-110 can not be obtained. It suggests that the selective photocatalytic oxidation of $\mathrm{RhB}$ derives from the combined effect of $\cdot \mathrm{OH}$ and $\cdot \mathrm{O}_{2}{ }^{-}$.

Therefore, the selective oxidation mechanism of CdS/Ag/a$\mathrm{TiO}_{2}$ can be illustrated in Fig. 7. Under Vis-light irradiation, $\mathrm{CdS} / \mathrm{Ag} / \mathrm{a}-\mathrm{TiO}_{2}$ can provide a large number of the photogenerated $\mathrm{e}^{-}$and $\mathrm{h}^{+}$due to the valence band (VB) electrons excitation of CdS and the formation of Z-scheme. ${ }^{63,64}$ Because the formation of $\mathrm{Z}$-scheme, the combination of $\mathrm{e}^{-}$and $\mathrm{h}^{+}$

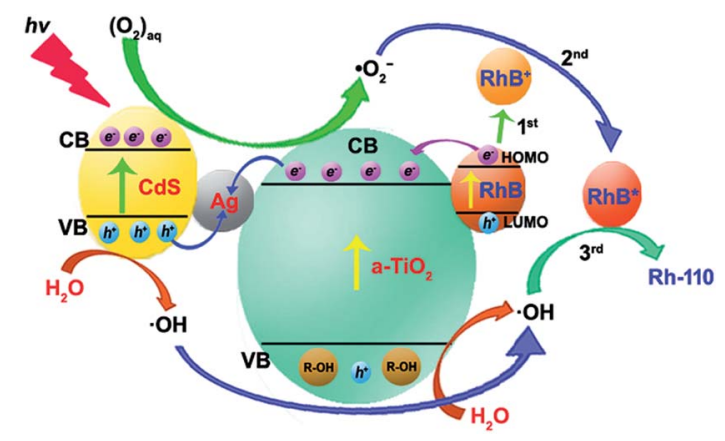

Fig. 7 Schematic diagram of the possible process for $\mathrm{CdS} / \mathrm{Ag} / \mathrm{a}-\mathrm{TiO}_{2}$ composites photocatalytic degrading RhB under light irradiation. should be suppressed during the complete photocatalysis oxidation (or unselective oxidation). However, the selective oxidation of $\mathrm{RhB}$ is the uncomplete photocatalysis oxidation process, we hope to reduce the effect of $\cdot \mathrm{OH}$ and obtain more $\cdot \mathrm{O}_{2}{ }^{-}$, the combination of $\mathrm{e}^{-}$(derived from $\mathrm{a}-\mathrm{TiO}_{2}$ and $\mathrm{RhB}$ ) and $\mathrm{h}^{+}$(derived from CdS QDs) at Ag NPs should be encouraged because it can improve the effect of $\cdot \mathrm{O}_{2}{ }^{-}$and obtain the high conversion ratio. Meanwhile, RhB lost $\mathrm{e}^{-}$of the highest occupied molecular orbital (HOMO) to $\mathrm{RhB}^{+}$with positively charged (Fig. 7, 1st) due to the photosensitized of RhB. The result is that $\mathrm{CdS} / \mathrm{Ag} / \mathrm{a}-\mathrm{TiO}_{2}$ shows the rich $\mathrm{e}^{-}$state. The photoisomerization of RhB chromophores can be seen as a feature of this phenomenon (Fig. 4d, red line). ${ }^{9,59}$ Under UV-light irradiation, a-TiO ${ }_{2}$ is excited and $\mathrm{h}^{+}$is captured, so that $\mathrm{CdS} / \mathrm{Ag} / \mathrm{a}-\mathrm{TiO}_{2}$ also shows the rich $\mathrm{e}^{-}$state (Fig. $4 \mathrm{~h}$, red line). According to eqn (1) to (7), a large number of $\cdot \mathrm{O}_{2}{ }^{-}$and a few $\cdot \mathrm{OH}$ are formed. Due to the electrostatic interaction, the reaction between $\cdot \mathrm{O}_{2}{ }^{-}$and $\mathrm{RhB}^{+}$is easy to form a transient state of $\mathrm{RhB}$ (RhB*, Fig. 7, 2nd) rather than the oxidation of $\mathrm{RhB}$, then $\mathrm{RhB}^{*}$ is oxidized by $\cdot \mathrm{OH}$ (Fig. 7, 3rd) to form Rh-110.

The transient state protection mechanism can be further confirmed by the scavenging experiments, especially the scavenging of $\cdot \mathrm{OH}$. Under Vis-light irradiation, as shown in Fig. $6 \mathrm{~b}$, the $\lambda_{\max }$ of RhB solution gradually shifts from $554 \mathrm{~nm}(\mathrm{RhB})$ to $498 \mathrm{~nm}$ (Rh-110). Compared to pure $\mathrm{CdS} / \mathrm{Ag} / \mathrm{a}-\mathrm{TiO}_{2}$ (Fig. 4b), the shifts rate is slowly. The reason is that $N$-deethylation reaction of $\mathrm{RhB}^{*}$ is also slowly when the $\cdot \mathrm{OH}$ is scavenged, so that the serious overoxidation of RhB or Rh-110 is avoided, finally, the conversion ratio of $\mathrm{Rh}-110$ reach to $85 \%$ at $140 \mathrm{~min}$ (Fig. $6 \mathrm{~b}$ and d).

However, under UV-light irradiation, although a large number of $\mathrm{RhB}^{*}$ is generated, the effect (amount) of $\cdot \mathrm{OH}$ is always weak during photocatalytic oxidation (Fig. 6h, red line), so the Rh-110 can be measured until $140 \mathrm{~min}$ (Fig. 4f). The reason is that $N$-deethylation reaction of $\mathrm{RhB}^{*}$ is more slowly when the $\cdot \mathrm{OH}$ is scavenged (Fig. 6f).

It means that the effect of $\cdot \mathrm{OH}$ cannot be neglected during the selective photocatalytic oxidation of RhB. When the effect of - $\mathrm{OH}$ is eliminated, the $N$-deethylation reaction of $\mathrm{RhB}^{*}$ can not be performed so that the selective photocatalytic oxidation of RhB disappears. Therefore, the rational controls of various ROS are an essential prerequisite for highly selective oxidation reactions. ${ }^{35} \mathrm{CdS} / \mathrm{Ag} / \mathrm{a}-\mathrm{TiO}_{2}$ certainly control radical generation during the selective photocatalytic oxidation of RhB.

When the effect of $\cdot \mathrm{OH}$ is bigger than the $\cdot \mathrm{O}_{2}{ }^{-}$, the blue-shift of $\lambda_{\max }$ disappear, suggesting that $\mathrm{RhB}$ can not be selective oxidized. As shown in Fig. 8, after scavenging $\cdot \mathrm{O}_{2}{ }^{-}$(Fig. 8a and e), $\cdot \mathrm{OH}$ (Fig. $8 \mathrm{~b}$ and $\mathrm{f}$ ), and $\mathrm{h}^{+}$(Fig. $8 \mathrm{c}$ and g), the blue-shift of $\lambda_{\text {max }}$ is not observed under both Vis- and UV-light irradiation. The photocatalytic degradation efficiency curves (Fig. 8d and h) demonstrate that the effect of $\cdot \mathrm{OH}$ is always bigger than the $\cdot \mathrm{O}_{2}{ }^{-}$. Because $\mathrm{c}-\mathrm{TiO}_{2}$ can not capture $\mathrm{h}^{+}$, the amount of $\mathrm{e}^{-}$is almost equate with the $\mathrm{h}^{+}$, the amount (effect) of $\cdot \mathrm{OH}$ increases. This result further confirms that the selective oxidation of RhB can be explained by the transient state protection mechanism. 

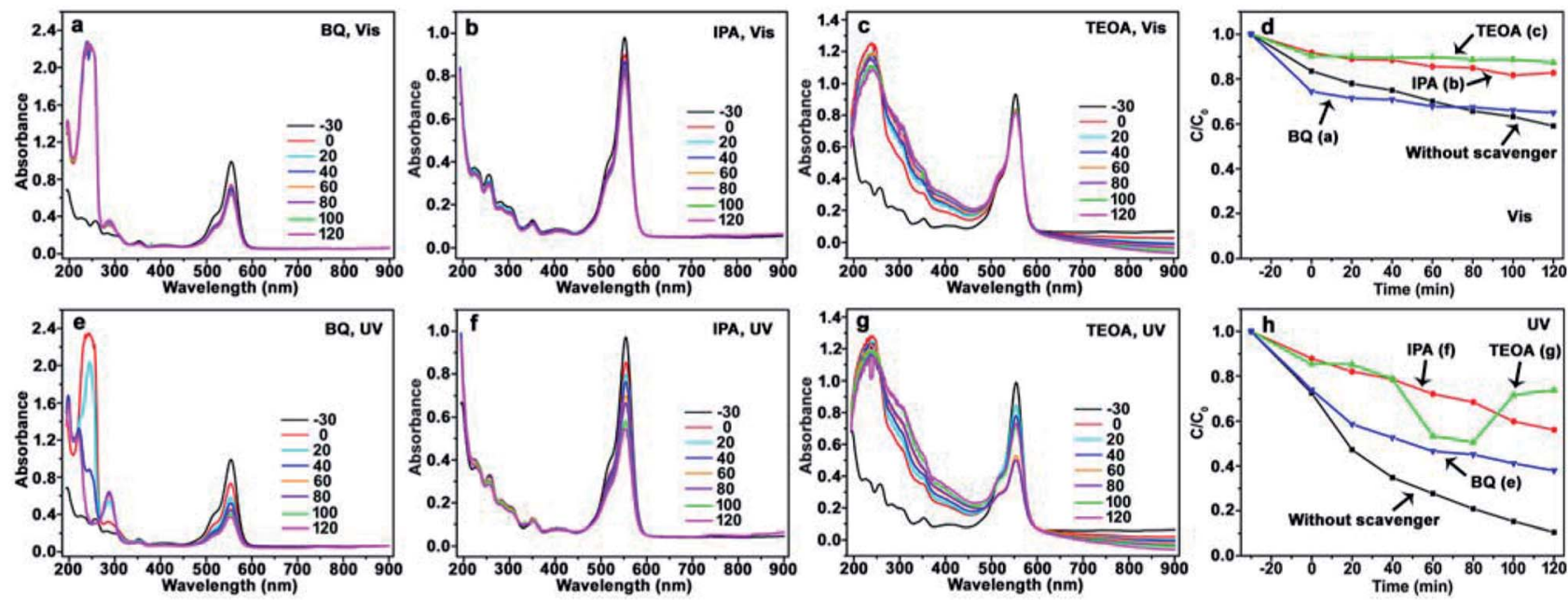

Fig. 8 Evolution of UV-Vis spectrum and photocatalytic degradation efficiency of RhB using $\mathrm{CdS} / \mathrm{Ag} / \mathrm{c}-\mathrm{TiO}_{2}$ photocatalyst. Scavengers: $\mathrm{BQ}$ (a), IPA (b), TEOA (c), and the corresponding degradation efficiency (d) under Vis-light; BQ (e), IPA (f), TEOA (g), and the corresponding degradation efficiency (h) under UV-light. The degradation efficiency curves without scavenger is inserted into (d) and (h) for comparison.

\section{Conclusion}

In summary, we designed and synthesized a $\mathrm{CdS} / \mathrm{Ag} / \mathrm{a}-\mathrm{TiO}_{2}$ composite with highly selective oxidation activity for the photocatalytic degradation of RhB. Due to the light-responding nature of CdS QDs and the LSPR effect of Ag NPs, CdS/Ag/a$\mathrm{TiO}_{2}$ composites can not only improve the conversion ratio of $\mathrm{RhB}$ to $\mathrm{Rh}-110$ in $82 \%$ at $80 \mathrm{~min}$ but also adjust the effect of ROS under Vis-light irradiation. A serial of the radical scavenging experiments confirm that $\mathrm{CdS} / \mathrm{Ag} / \mathrm{a}-\mathrm{TiO}_{2}$ composite exhibits the good photocatalytic selective oxidation activity, because $\mathrm{CdS} / \mathrm{Ag} /$ a- $\mathrm{TiO}_{2}$ composite can modulate the effect of $\cdot \mathrm{O}_{2}{ }^{-}$and $\cdot \mathrm{OH}$ during the photocatalytic oxidation of RhB. Meanwhile, this work also further endorses the transient state protection mechanism of $\mathrm{RhB}$ as reported in previous work, that is, the effect of $\cdot \mathrm{O}_{2}{ }^{-}$is more important than the $\cdot \mathrm{OH}$ in the forming process of Rh-110, because $\cdot \mathrm{O}_{2}{ }^{-}$can react with $\mathrm{RhB}$ to form the transient state of conjugated xanthene structure of $\mathrm{RhB}$ and avoid the serious overoxidation toward RhB or Rh-110, but the effect of $\cdot \mathrm{OH}$ can not be neglected. Therefore, this may provide a new strategy for modulating radical generation in the photocatalysis of water phase.

\section{Conflicts of interest}

There are no conflicts to declare.

\section{Acknowledgements}

This work was financially supported by the National Natural Science Foundation of China (Grant No. 21573059 and U1704251), Science and Technology Research Project of Henan Province (No. 152102310311, 182102210082), the Key Scientific Research Project of Colleges and Universities in Henan (No. 16A150032), Dr. Start-up Project Funding of Henan Normal University (qd16114). Innovation Funds for Postgraduate (No. YL201512, YL2017xx).

\section{Notes and references}

1 R. Li, H. Han, F. Zhang, D. Wang and C. Li, Energy Environ. Sci., 2014, 7, 1369-1376.

2 L. Hu, H. Yuan, L. Zou, F. Chen and X. Hu, Appl. Surf. Sci., 2015, 355, 706-715.

3 C. Chen, W. Zhao, J. Li, J. Zhao, H. Hidaka and N. Serpone, Environ. Sci. Technol., 2002, 36, 3604-3611.

4 T. Wu, G. Liu, J. Zhao, H. Hidaka and N. Serpone, J. Phys. Chem. B, 1998, 102, 5845-5851.

5 J. Zhuang, W. Dai, Q. Tian, Z. Li, L. Xie, J. Wang, P. Liu, X. Shi and D. Wang, Langmuir, 2010, 26, 9686-9694.

6 P. Lei, C. Chen, J. Yang, W. Ma, J. Zhao and L. Zang, Environ. Sci. Technol., 2005, 39, 8466-8474.

7 H. Park and W. Choi, J. Phys. Chem. B, 2005, 109, 1166711674.

8 Z. S. Seddigi, M. A. Gondal, S. G. Rashid, M. A. Abdulaziz and S. A. Ahmed, J. Mol. Catal. A: Chem., 2016, 420, 167-177.

9 H. Liang, Z. Jia, H. Zhang, X. Wang and J. Wang, Appl. Surf. Sci., 2017, 422, 1-10.

10 A. Fujishima and K. Honda, Nature, 1972, 238, 37-38.

11 J. Zhang, S. Meng, X. Ye, C. Ling, S. Zhang, X. Fu and S. Chen, Appl. Catal., B, 2017, 218, 420-429.

12 J. B. Joo, M. Dahl, N. Li, F. Zaera and Y. Yin, Energy Environ. Sci., 2013, 6, 2082.

13 R. A. Doong, T. C. Hsieh and C. P. Huang, Sci. Total Environ., 2010, 408, 3334-3341.

14 Y. Shiraishi, H. Sakamoto, K. Fujiwara, S. Ichikawa and T. Hirai, ACS Catal., 2014, 4, 2418-2425.

15 X. Jia, R. Dai, D. Lian, S. Han, X. Wu and H. Song, Appl. Surf. Sci., 2017, 392, 268-276.

16 J. Gou, Q. Ma, X. Deng, Y. Cui, H. Zhang, X. Cheng, X. Li, M. Xie and Q. Cheng, Chem. Eng. J., 2017, 308, 818-826.

17 X. Dai, M. Xie, S. Meng, X. Fu and S. Chen, Appl. Catal., B, 2014, 158-159, 382-390. 
18 M. Bellardita, E. I. García-López, G. Marci, I. Krivtsov, J. R. García and L. Palmisano, Appl. Catal., B, 2018, 220, 222-233.

19 P. Zhang, Y. Liu, B. Tian, Y. Luo and J. Zhang, Catal. Today, 2017, 281, 181-188.

20 M. J. Lima, P. B. Tavares, A. M. T. Silva, C. G. Silva and J. L. Faria, Catal. Today, 2017, 287, 70-77.

21 K. Czelej, K. Cwieka, J. C. Colmenares, K. J. Kurzydlowski and Y. J. Xu, ACS Appl. Mater. Interfaces, 2017, 9, 3182531833.

22 X. Liang, X. Yang, G. Gao, C. Li, Y. Li, W. Zhang, X. Chen, Y. Zhang, B. Zhang, Y. Lei and Q. Shi, J. Catal., 2016, 339, 68-76.

23 B. Zhang, J. Li, Y. Gao, R. Chong, Z. Wang, L. Guo, X. Zhang and C. Li, J. Catal., 2017, 345, 96-103.

24 W. Huang, B. C. Ma, H. Lu, R. Li, L. Wang, K. Landfester and K. A. I. Zhang, ACS Catal., 2017, 7, 5438-5442.

25 Z. Yang, X. Xu, X. Liang, C. Lei, Y. Wei, P. He, B. Lv, H. Ma and Z. Lei, Appl. Catal., B, 2016, 198, 112-123.

26 E. Skliri, S. Papadogiorgakis, I. N. Lykakis and G. S. Armatas, ChemPlusChem, 2017, 82, 136-143.

27 S. Samanta, S. Khilari, D. Pradhan and R. Srivastava, ACS Sustainable Chem. Eng., 2017, 5, 2562-2577.

28 A. Franco, S. De, A. M. Balu, A. A. Romero and R. Luque, ChemistrySelect, 2017, 2, 9546-9551.

29 H. Park, H.-i. Kim, G.-h. Moon and W. Choi, Energy Environ. Sci., 2016, 9, 411-433.

30 A. Busiakiewicz, A. Kisielewska, I. P. ński and D. Batory, Appl. Surf. Sci., 2017, 401, 378-384.

31 J. Schneider, M. Matsuoka, M. Takeuchi, J. Zhang, Y. Horiuchi, M. Anpo and D. W. Bahnemann, Chem. Rev., 2014, 114, 9919-9986.

32 A. Wold, Chem. Mater., 1993, 5, 280-283.

33 S. Rasalingam, C. M. Wu and R. T. Koodali, ACS Appl. Mater. Interfaces, 2015, 7, 4368-4380.

34 J. Lv, H. Gao, H. Wang, X. Lu, G. Xu, D. Wang, Z. Chen, X. Zhang, Z. Zheng and Y. Wu, Appl. Surf. Sci., 2015, 351, 225-231.

35 B. Zhang, J. Li, B. Zhang, R. Chong, R. Li, B. Yuan, S.-M. Lu and C. Li, J. Catal., 2015, 332, 95-100.

36 X. Lang, X. Chen and J. Zhao, Chem. Soc. Rev., 2014, 43, 473486.

37 J. Kou, C. Lu, J. Wang, Y. Chen, Z. Xu and R. S. Varma, Chem. Rev., 2017, 117, 1445-1514.

38 T. He, L. Zu, Y. Zhang, C. Mao, X. Xu, J. Yang and S. Yang, ACS Nano, 2016, 10, 7882-7891.

39 H. Yu, W. Chen, X. Wang, Y. Xu and J. Yu, Appl. Catal., B, 2016, 187, 163-170.

40 H. Yu, X. Huang, P. Wang and J. Yu, J. Phys. Chem. C, 2016, 120, 3722-3730.

41 M. Aliabadi, Sep. Purif. Technol., 2017, 174, 145-149.

42 P. Shao, J. Tian, Z. Zhao, W. Shi, S. Gao and F. Cui, Appl. Surf. Sci., 2015, 324, 35-43.
43 K. Song, X. Wang, Q. Xiang and J. Xu, Phys. Chem. Chem. Phys., 2016, 18, 29131-29138.

44 X. Wang, Z. Jia, F. Liu, H. Liang, X. You, K. Wang, X. Lou, W. Shuang, L. Xiao, B. Cai and L. Yang, RSC Adv., 2016, 6, 48985-48994.

45 R. Freeman and I. Willner, Chem. Soc. Rev., 2012, 41, 40674085.

46 M. Tayebi, M. Tavakkoli Yaraki, M. Ahmadieh, M. Tahriri, D. Vashaee and L. Tayebi, Colloid Polym. Sci., 2016, 294, 1453-1462.

47 S. B. Taieb, T. N. P. Truong, S. Chaguetmi, J. B. Naceur, A. Bardaoui, M. Gannouni, P. Decorse, L. Mouton, S. Nowak, F. Mammeri, R. Chtourou and S. Ammar, J. Photochem. Photobiol., A, 2017, 332, 337-344.

48 S. Li, D. Meng, L. Hou, D. Wang and T. Xie, Appl. Surf. Sci., 2016, 371, 164-171.

49 F. Q. Zhou, J. C. Fan, Q. J. Xu and Y. L. Min, Appl. Catal., B, 2017, 201, 77-83.

50 P. Wang, Y. Sheng, F. Wang and H. Yu, Appl. Catal., B, 2018, 220, 561-569.

51 D. H. Yu, X. Yu, C. Wang, X. C. Liu and Y. Xing, ACS Appl. Mater. Interfaces, 2012, 4, 2781-2787.

52 M. M. Viana, N. D. S. Mohallem, D. R. Miquita, K. Balzuweit and E. Silva-Pinto, Appl. Surf. Sci., 2013, 265, 130-136.

53 Z. Jiang, K. Qian, C. Zhu, H. Sun, W. Wan, J. Xie, H. Li, P. K. Wong and S. Yuan, Appl. Catal., B, 2017, 210, 194-204.

54 Y. Wei, J. Jiao, Z. Zhao, W. Zhong, J. Li, J. Liu, G. Jiang and A. Duan, J. Mater. Chem. A, 2015, 3, 11074-11085.

55 X. Zhang, Y. Li, J. Zhao, S. Wang, Y. Li, H. Dai and X. Sun, J. Power Sources, 2014, 269, 466-472.

56 X. Zhang, L. Wang, C. Liu, Y. Ding, S. Zhang, Y. Zeng, Y. Liu and S. Luo, J. Hazard. Mater., 2016, 313, 244-252.

57 Y. Gao, P. Fang, Z. Liu, F. Chen, Y. Liu, D. Wang and Y. Dai, Chem.-Asian J., 2013, 8, 204-211.

58 W. Li, C. Feng, S. Dai, J. Yue, F. Hua and H. Hou, Appl. Catal., $B, 2015$, 168-169, 465-471.

59 W. Wang, M. Ye, L. He and Y. Yin, Nano Lett., 2014, 14, 16811686.

60 H. Liu, Y. Hu, Z. Zhang, X. Liu, H. Jia and B. Xu, Appl. Surf. Sci., 2015, 355, 644-652.

61 C. Dong, K.-L. Wu, X.-W. Wei, J. Wang, L. Liu and B.-B. Jiang, Appl. Catal., A, 2014, 488, 11-18.

62 A. S. Vorokh, N. S. Kozhevnikova, T. I. Gorbunova, O. I. Gyrdasova, I. V. Baklanova, L. Y. Buldakova, M. Y. Yanchenko, A. M. Murzakaev, E. V. Shalaeva and A. N. Enyashin, J. Alloys Compd., 2017, 706, 205-214.

63 D. Wang, H. Shen, L. Guo, F. Fu and Y. Liang, New J. Chem., 2016, 40, 8614-8624.

64 J. Li, S. K. Cushing, P. Zheng, T. Senty, F. Meng, A. D. Bristow, A. Manivannan and N. Wu, J. Am. Chem. Soc., 2014, 136, 8438-8449. 